\title{
Exploring Coaching for Powerful Technology Use in Education
}

Tina Ehsanipour \& Florencia Gomez Zaccarelli Center to Support Excellence in Teaching - Stanford University July 2017

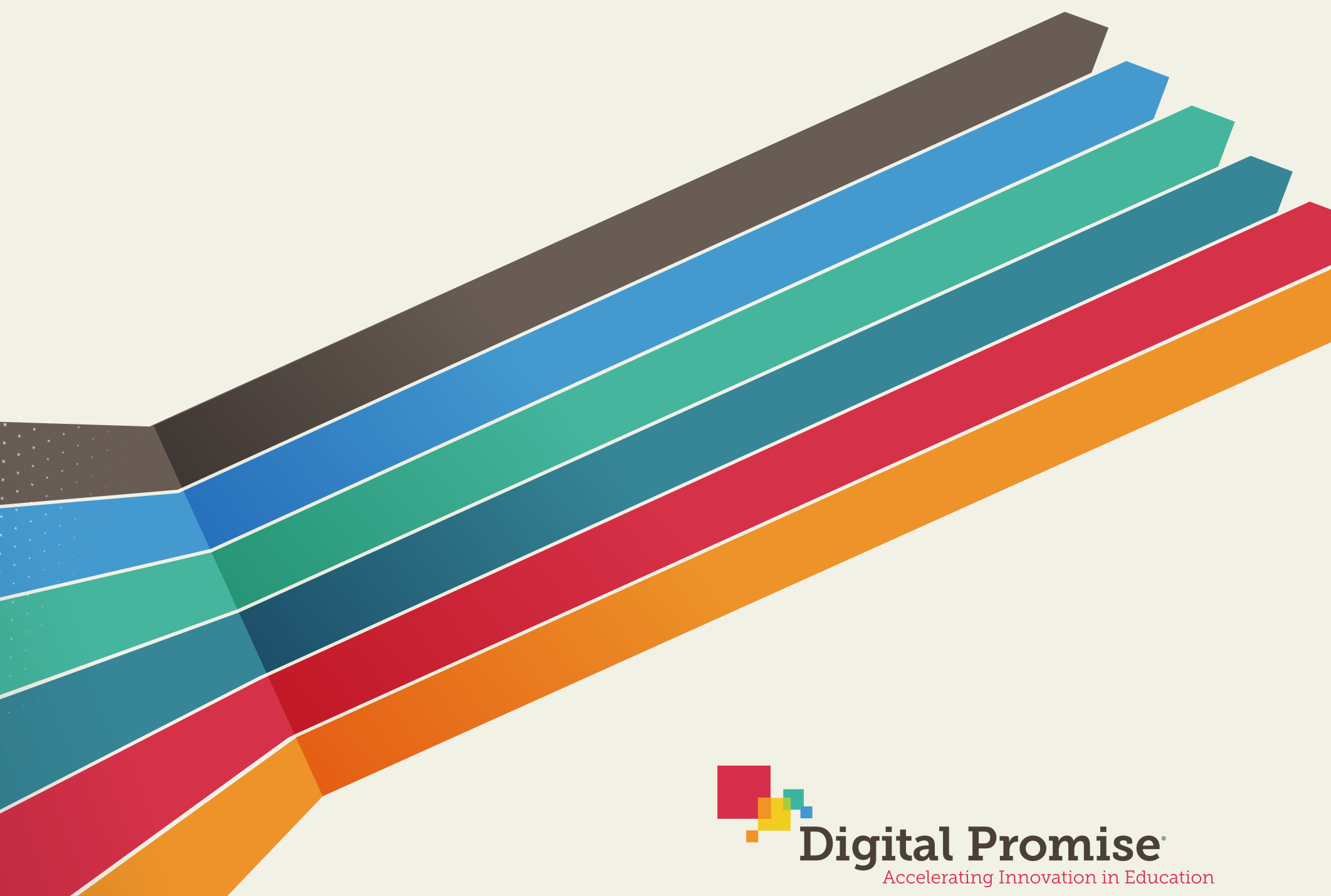




\section{Table of Contents}

Introduction $\ldots \ldots \ldots \ldots \ldots \ldots \ldots \ldots \ldots \ldots \ldots$

A Definition of Coaching $\ldots \ldots \ldots \ldots \ldots \ldots \ldots \ldots$

Coaching as Professional Development ............ 5

Frameworks for Instructional Coaching . . . . . . . . 6

Evidence of the Impact of Coaching in Teaching Practice . . 7

Features of Effective Coaching $\ldots \ldots \ldots \ldots \ldots \ldots \ldots \ldots \ldots$

Coaching for Meaningful

Technology Use in the Classroom . . . . . . . . . . . . 10

Designing and Implementing Instructional Coaching Programs . 12

Evaluation of Instructional Coaching ................. 13

Technology Tools for Implementing Coaching ............. 14

Conclusion ............................... 15

References .......................... 16 


\section{Introduction}

Educators, administrators, and policymakers have all been exploring ways to ensure that all students have access to a high quality education. Considering the technological advances that currently exist, these conversations about equity must also happen in the context of technology education. What is the role of technology in the 21st century classroom? How do we best provide teachers with the time, support, and space to learn how to use new technological tools and resources effectively and to support deeper learning?

According to James, et al. (2011), by fully integrating technology in their classrooms, teachers can create "authentic learning experiences emphasizing collaboration, creativity, and innovation," which will then prepare them to be "productive digitalage citizens" (p. 2). Similarly, the National Education Technology Plan (2017) states:

Technology can be a powerful tool for transforming learning. It can help affirm and advance relationships between educators and students, reinvent our approaches to learning and collaboration, shrink long-standing equity and accessibility gaps, and adapt learning experiences to meet the needs of all learners. (...) However, to be transformative, educators need to have the knowledge and skills to take full advantage of technologyrich learning environments (p. 3-5).

Furthermore, Reinhart, Thomas, and Toriskie (2011) state that the higher the percentage of free and reduced lunch students in a school, the less technology is used to promote higherorder thinking and the less access there is to technology facilitators. These findings point to the growing importance of having effective professional development for teachers, especially in the use of technology. However, the oneshot professional development sessions of the past are simply not as meaningful or impactful as more consistent, long-term, contentspecific opportunities. Coaching can be one way to give educators the knowledge and skills they need to grow professionally and, in turn, serve the diverse needs of their students.

In this paper we:

- Define coaching and explore how it fits in the larger scope of professional development.

- Provide an overview of some of the frameworks for coaching that exist in the literature.

- Present evidence of the impact of coaching in teaching.

- Delve into what it means to coach for meaningful technology use in the classroom, and how using technology in the coaching process itself can serve as a model for teachers.

- Provide insights on how to guide the design, implementation and evaluation of coaching programs. 


\section{A Definition of Coaching}

Coaching has long been associated with other fields, most notably sports and business. The goal in all these fields is essentially the same - to improve individual performance and organizational effectiveness (Kurz, Reddy, \& Glover, 2017). But what exactly do we mean by coaching in the world of education? There are many different answers to this question in the literature. Some define coaching as a tool to develop teachers' ability to identify how helpful an instructional strategy is in supporting student learning (Russo, 2004). Others describe teacher coaching as a mechanism to achieve fidelity of implementation of novel teaching practices (Devine, Meyers, \& Houssemand, 2013). Salavert (2015) describes coaching as an "apprenticebased approach to support professional and personal development towards achieving set goals" (p. 2). Sutton, et al. (2011) add that a coach "works collaboratively with a teacher" (p. 15). The term collaboratively captures the essence of why coaching and mentoring are actually different from one another, although the two terms are sometimes used interchangeably. They suggest slightly different relationships between the two parties involved. A mentorship implies more of a hierarchical relationship in which the mentor serves as a role model, whereas coaching suggests a partnership-type relationship in which the coach encourages growth through his/her expertise (Salavert, 2015). Moreover, in a coaching relationship, teachers and coaches engage in a sustained professional dialogue aimed to improve teaching by developing instructional skills (Lofthouse, Leat, Towler, Hall, \& Cummings, 2010).

We use the term coaching, rather than mentoring, in order to better capture the collaboration between coach and teacher in the coaching relationship, which is a vital component in effective teacher support programs. 



\section{Frameworks for Instructional Coaching}

Before we delve into the research on the impact of coaching, it is important to expand upon some of the coaching frameworks present in the world of coaching in education.

Knight (2007) outlines some common forms of coaching, including:

1 Executive coaching, which has been most researched because of its popularity in the business world. In this form of coaching, the coach helps the client develop competency in a specific skill/area.

2 Coactive coaching, which entails the coach taking more of a holistic approach by striving to help the client feel fulfilled and balanced.

3 Cognitive Coaching ${ }^{1}$, which he argues is the typical model found in many American schools. Because this model is based on the idea that beliefs must change before actions, coaches help teachers reflect on their beliefs as a way to change their behaviors.

4 Instructional coaching, which involves coaches helping teachers to "incorporate research-based instructional practices" (p. 12).

Kurz, et al. (2017) offer what they term a "multidisciplinary" framework, which arguably combines some of the models mentioned by Knight. Their framework focuses the scope of coaching on three specific areas: skills, process, and development. By being coached on more than just specific skills, teachers are given the support they need to see how they do something (process) matters just as much as what they do (skills). The "development" aspect of the framework refers to how the coach then helps the teacher apply the skills and processes to move towards specific, decided-upon goals.
From a perspective on the features of coaching, White, et al. (2015) organize what researchers have found to be "essential ingredients" of coaching into a "coherent model" that consists of coach factors, teacher factors, and coach-teacher interaction factors:

- Coach factors:

- Coach has content expertise, classroom experience, technology proficiency, and interpersonal skills.

- Coach co-plans goals with teacher and engages in a cycle of classroom video reflection and collaborative discussion, which leads to additional planning for future lessons, etc.

- Teacher factors:

- Teacher is willing to engage in the process of collaborating with coach.

- Teacher has an asset lens, genuinely believing that students are capable of succeeding.

- Coach-teacher interaction factors:

- There is rapport, mutual respect, and trust between the coach and teacher

- Coaching conversations consist of positive feedback so the process does not feel evaluative.

These frameworks contribute to the understanding of diverse forms of coaching models that could potentially support different needs, such as instructional coaching that is especially geared towards supporting teaching instruction in a specific domain of knowledge.

${ }^{1}$ Cognitive Coaching is a service-marked term (SM). 


\section{Evidence of the Impact of Coaching in Teaching Practice}

There is certain agreement that the evidence of the impact of coaching in teaching practice is still a work in progress and there is still not enough knowledge about this relationship (Cornett \& Knight, 2009). However, we know that effective teachers can have an impact on student achievement and make a significant difference compared to other school factors (Sanders, Wright, \& Horn, 1997). If teaching skills and practices that support students effectively play an important role in their learning, developing those skills and practices is a priority.

Professional development for teachers is vital in developing the necessary skills and practice to deliver effective teaching. A growing body of empirical research has helped identify the structure, content and outcomes of effective professional development. Desimone (2009) has identified five characteristics of professional development: a focus on content and how students learn that content; active learning; coherence with both teacher knowledge and beliefs and local policies; duration; and collective participation. There is an emergent consensus that these features are associated with positive outcomes. However, the mixed results from empirical studies on the impact of PD on teachers and students indicate that these features of professional development are a necessary condition but, by themselves, not sufficient to affect change (Garet et al., 2011). One reason is that they are not specific enough to guide PD design decisions. Coaching, as a professional development strategy, might provide the specificity that the current research on professional development has not found in other strategies.

Although evidence of its effectiveness is still thin, coaching has become one of the forms of professional development that has grown faster in the past years (Darling-Hammond et al., 2009). A number of comparative studies on teachers who had been coached show that they appropriately implement desired practices in their classrooms (Knight, 2007). Kraft, Blazar and Hogan (2016) developed the first meta-analysis of studies that examine causal effects between teacher coaching and instructional practice and student achievement. Kraft and colleagues' study compared different coaching models with specific features that could influence the effects of a program, and compared programs of different sizes to identify the challenges of scaling these programs. This study found large positive effects of coaching on teachers' instructional practice and a meaningful positive impact of coaching in student achievement.

Conversely, another study found that coached teachers perceived themselves as more confident in teaching, but were not assessed as more effective than teachers who did not receive coaching (Veenman, Denessen, Gerrits, \& Kenter, 2001). Moreover, when examining the features that make coaching more effective, Kraft and colleagues did not find "any clear evidence of systematic differences in effect sizes based on features of the coaching model" $(2016$, p. 20).

These mixed results provide a perspective into a field that needs to be studied more deeply, in particular, on the mechanisms that make coaching more effective than other forms of professional development. Coaching, as a process to support professional learning ought to promote instructional practices that contribute to schools' improvement under their specific contextual needs. 


\section{Features of Effective Coaching}

Although empirical research on the mechanisms that make instructional coaching more effective is still modest, there are some features that might contribute to the effectiveness of coaching as a form of professional development. A study conducted by Blazar and Kraft (2015) showed that a combination of focus on instructional delivery and time spent on coaching with that focus is associated with positive and statistically significant improvement in coached teachers' practices. In contrast, time spent in coaching with a focus on behavioral management is associated with negative and statistically significant decrease in the quality of teachers' practices, including practices directly related to behavioral management.

In another study of coaching in thirteen schools in four different regions in England, researchers identified that challenging teachers supported the emergence of dissonance between planning and enacting instruction and its relationship with underlying teachers' beliefs, favoring reflection. In spite of its benefits, challenging teachers as part of coaching was not common (Lofthouse et al., 2010). This study also found that positive outcomes were mediated by the use of video to analyze teacher-students interactions with coached teachers. Concordantly, the use of web-based platforms that include video of classrooms for virtual coaching is a promising approach for connecting effective coaches with teachers, reducing costs of commute and allowing coaches to take on an increased load of teachers (Kraft et al., 2016).

Teacher buy-in is as relevant as other features such as the level of expertise and enthusiasm of coaches. In their meta-analysis, Kraft and colleagues found positive effects of coaching on teachers' instructional practice in programs where participants volunteer to participate (2016). Trust and respect for teachers' autonomy and decision-making ability is critical in building a coaching relationship where teachers are willing to participate. The coaching can be adversely affected when the role of coach is combined with that of evaluator, an approach that some districts take in fulfilling the need for effective coaches (Hanover Research, 2015; Kraft et al., 2016). In facing this challenge, researchers instead recommend providing opportunities for professional development especially designed for coaches to increase their effectiveness.

The limited evidence about the features of effective coaching is stressed if the focus narrows down to coaching for technology; however, some insights to guide future work have been identified. Supported by ISTE, James and colleagues (2011) report on the role of coaching, combined with professional learning communities, as a key component of an approach to teacher professional development on the effective use of technology for the digital age. They state,

Coaching support for teachers is a powerful means of both modeling and harnessing the potential of technology to improve teaching and learning. Teachers who receive coaching in the use of technology tools to improve student learning, and who learn from and collaborate with peers via professional learning communities, will develop confidence and effectiveness in designing and supporting technology-rich environments that maximize student learning. $(2011$, p. 3)

Drawing on three models of coaching, the authors report on a number of examples that illustrate the potentials of coaching for improving instruction with technology tools. Using a cognitive coaching model, the eMINTS program helps teachers introduce concepts from professional development into their classroom practice by "modeling instruction, lesson planning, technology assistance, reflective practice, and problem solving around program implementation" (2011, p. 9). Research conducted in 2010 on the eMINTS program found that both student achievement outcomes and teacher 
satisfaction increased when instructional technology professional development supported the alignment between instructional problems and key concepts with technology tools.

The Kansas Coaching Project uses the instructional coaching model, which is built on The Big Four framework that considers classroom management, content planning, instruction, and assessment for learning. This project utilizes instructional coaching for achieving effective teacher learning and involves the use of technology in the coaching practice. The Kansas Coaching Project identified seven practices implemented by coaches to facilitate learning and integration of teaching practices: 1 ) teacher choice of engagement in the coaching relationship, 2) teacher selection of the teaching practice to focus on, 3) shared understanding of the teaching practice as well as how to observe it between teacher and coach, 4) teacher enactment of the practice, 5) coach observation of the practice, 6 ) encouragement of teacher to use the practice and identify how to improve its implementation, and finally, 7) habitual implementation of the practice by the teacher.
The third model described by James and colleagues is peer coaching, which has been adopted by the Microsoft initiative, Partners in Learning program, to support and implement coaching both in the U.S. and internationally. The model involves the training of teachers to support their colleagues in the integration of technology with a focus on collaboration among teachers. In a model developed by Peer-Ed, coaches and their colleagues identify their needs and how to collaborate and follow the five stages of the model: assessment of teachers' technology skills and instructional strategies to define a project to work on in the coaching relationship and the resources and skills needed to carry out the project; setting up reasonable goals linked to the school's goals and curricular standards; coaches use a learning activity checklist to evaluate a lesson, project or unit; coaches model a technology-rich lesson or plan to co-teach a lesson with the teacher; coaches support the analysis of the lesson or project and debrief with participant teachers. These three models applied in different coaching initiatives provide a perspective on how to approach coaching for technology integration and develop effective coaching features for the professional development of teachers.

\section{Trust and respect for teachers' autonomy and decision-making ability is critical in building a coaching relationship where teachers are willing to participate.}




\section{Coaching for Meaningful Technology Use in the Classroom}

The Partnership for 21st Century Skills names the four skills (4Cs) that students need to develop in order to be successful: Communication, Collaboration, Critical Thinking, and Creativity. Technology can be used as a tool to support these $4 \mathrm{Cs}$ in various content areas; however, we must be mindful about how exactly we coach teachers to meaningfully integrate technology into their classrooms.

Viewing technology as a possible solution to improving student learning, especially for atrisk students, is not a new concept, but the results are mixed. Models in which technology is used in more "passive" ways (essentially like a computerized workbook) have not achieved the results originally hoped for (Darling-Hammond, Zielezinski, \& Goldman, 2014). While these forms of technology integration are easily "packaged" and distributed for school consumption, they do not push students towards mastery of the 4Cs. Just as we have moved past the "workbook as learning" methodology in classroom instruction, so too must we do so with technology. It is not equitable for more privileged students to be using technology in exciting, new ways while students from lower-resourced schools are only using technology for reading recovery programs. We must use technology in more innovative ways for all student populations.

\section{Darling-Hammond, Zielezinski, \& Goldman} (2014) argue the following three factors must be present in order to best serve the needs of at-risk students: (1) Interactive learning. Because technology can expose students to content in multiple ways, difficult content can become more accessible to more students; (2) Use of technology to explore and create rather than for "drill and practice." Rather than being the consumers of technology, students can become the creators. When students are using technology to create multimedia projects (such as digital storytelling or video production), they are not only learning valuable technology skills and developing critical/ creative thinking skills, they are also actively engaging in their learning; and (3) The right blend of teachers and technology. In an ideal situation, each student has access to his/her own computer and there are plenty of opportunities for peer interaction and teacher support.

In response to the argument for "flipped" classrooms, in which students use technology at home as a substitute for direct instruction that would typically occur during classroom time, Darling-Hammond, Zielezinski, \& Goldman (2014) state that because this model has not been used in $\mathrm{K}-12$ classrooms to the extent that it has in higher education, there is not enough research about its effectiveness with $\mathrm{K}-12$ students. However, they firmly believe that students will find success with a technologyintegration model that is "more interactive, proactive, and teacher-supported," assuming that there are "adequate supports for teacher learning about how to use the technologies and pedagogies that are recommended" as well as technical assistance for teachers to "manage the hardware, software, and connectivity that make technology infusion possible" (p. 14-15).

Coaching, rather than a one-shot technologyfocused professional development session, may be a better way to provide these supports that teachers need to meaningfully and seamlessly integrate technology into their classrooms. While much of the research can be applied in the context of technology-focused coaching, it is worth mentioning some of the additional challenges that a technology coach may face. 
Given that the research supports the importance of content-based coaching, it is vital to determine what "content" a technology coach is helping teachers master - is technology the content or is the actual subject matter the content? Ertmer $\&$ Ottenbreit-Leftwich (2013) offer this insight:

(...) technology integration is not the ultimate goal; rather the goal is to engage students in authentic problem-solving, using the most effective and efficient tools available. As such, technology plays a supportive rather than starring role, enabling the successful achievement of both instructional and learning goals. (...) Technology use must, first and foremost, be designed to support learning goals, not the other way around" (p. 6-7).

If technology should indeed play the "supportive" rather than "starring" role, then it would be ideal for the coach to have not only expertise in the use of technology, but also in the specific content area of the teacher. This may pose a challenge in schools where there is at most one technology coach to begin with. One possible solution to this problem is to have a technology expert coach the coaches. In other words, the instructional coaches with expertise in different content areas would receive training and support to expand their knowledge of technology before applying it to their own content areas. By employing such a model, content-specific coaches are able to coach teachers in areas in which they have expertise, putting the content in the "starring" role and technology in the "supportive role." Still following the idea of fore fronting domainspecific knowledge and using technology as support, an alternative to this model is suggested by Dinse de Salas and colleagues (2016) as a collaboration between a coach expert in technology and coached teachers who are the experts in the content of their domains.

Referencing Jonassen's seminal work on technology and the classroom (1996), it becomes apparent that much in the world of technology and the classroom has remained the same. He states, "[t]raditionally, instructional technologies have been used as media for conveying information, much as teachers do... Using computers to 'teach' students in this traditional way is not appropriate because it does not mindfully engage students in making meaning" (p. 1). Jonassen stresses the importance of students learning "with" as opposed to "from" technology. He advocates for the use of computers as "mindtools" that allow students to not simply acquire knowledge, but rather "construct" it. Despite this study being almost 20 years old, there is much that we can still learn from it since the use of technology in the classroom has seen slow change.

Ertmer \& Ottenbreit-Leftwich (2013) build on Jonassen's work when they call for a shift from "technology integration" to what they term "technology-enabled learning." They point out that decades after Jonassen's paper was published, "we seem no closer to envisioning and achieving the kinds of powerful, purposeful uses needed to support meaningful student outcomes" and that "our efforts in both teacher education and professional development must emphasize how, not what, technology should be used to achieve meaningful outcomes" (p. 175)

This "mindset" shift that needs to occur suggests that the Cognitive Coaching model, referenced by Knight (2007), would be essential to coaching teachers. As Garcia, et al. (2013) state, "the literature indicates that changing how teachers approach their practice will eventually lead to a positive relation in student achievement..." (p. 10). Therefore, educators' beliefs about the best use of technology in the classroom must first be shifted before their actual uses of the technology can be influenced. Perhaps then teachers will move away from technology being used as a "delivery tool" (Ertmer \& OttenbreitLeftwich, 2013) to more of a collaborative partner as Jonassen had envisioned. 


\section{Designing and Implementing Instructional Coaching Programs}

In supporting instruction, coaching has emerged as a strong form of professional development, especially when complemented with other strategies to support teacher learning. Hence, the design and implementation of instructional coaching as a program becomes highly relevant. As described previously, although still initial, empirical research supports some features of effective coaching that can be considered in the design of new programs such of focus on instructional delivery rather than behavioral management (Kraft et al., 2016), a challenging approach in coaching (Lofthouse et al., 2010), the development of trust and respect in the coaching relationship, as well as collaboration between coach and coached teachers. Moreover, instructional coaching has to be a component of a major effort in support of teaching improvement. As the Annenberg Institute for School Reform asserts, "[i]nstructional coaching is fundamentally about teachers, teacher leaders, school administrators, and central office leaders examining practice in reflective ways, with a strong focus on student learning and results as the ultimate barometer of improvement" (King et al., 2004, p. 3). Therefore, coaching as a systemic approach to teaching improvement stresses the importance of including stakeholders at different levels of the school system in order to articulate initiatives and goals. As the Annenberg's report advises, coaching programs should be "a collective enterprise embedded in the larger district context, rather than as an isolated project" (King et al., 2004, p. 10).

In a similar approach, the joint report of The University of Florida Lastinger Center for Learning, Learning Forward, and Public Impact (2016), recommends to develop coaching programs with system vision and strong commitment that includes a shared vision among leaders, a system's overall strategy with coaching at the center, clear roles for all stakeholders, adequate human and financial resources, and aligned policies to supporting coaching. This is the first of six pillars that the group proposes for providing all teachers high quality coaching that is part of their every day practice in schools. According to this group, other fundamental components of an effective coaching program should consider guidelines for recruitment and selectivity of coaches that can demonstrate a combination of expertise and skill, shared responsibility among different leaders to provide clear and coordinated messages to teachers regarding the goals of their improvement, high quality professional development for coaches to develop their skills with continuous support from the system, clarity of the coach's role and sustained opportunities for teachers to interact with coaches also supporting the development of a coaching culture, and finally, incentives for effective teachers to consider taking the role of coach with increasing monetary compensations and an eye on the sustainability of initiatives.

In integrating technology for teaching and learning, coaching can contribute to developing teachers' understanding of the leveraging powers of technology for instruction. In 2011, the International Society for Technology in Education (ISTE) released the ISTE Standards for Coaches that provide a valuable framework for designing coaching programs and implementing them with fidelity (ISTE, 2011). The standards include the following components:

Visionary Leadership. The capacity of technology coaches to develop and implement a shared vision for integration of technology in service of excellence and transformation of instruction.

Teaching, Learning and Assessments. Technology coaches provide support for using technology effectively in assessing student learning, differentiating instruction, and providing high quality learning experiences for all students.

Digital Age Learning Environments. Coaches promote the use of digital learning environments to support the integration of 
online and blended learning, digital content, and collaborative learning networks, as well as evaluating digital tools and supporting communication locally and globally.

Professional Development and Program Evaluation. Technology coaches develop assessment of needs, technology professional learning opportunities, and evaluation of the impact of technology on instructional practice and student learning.

Digital Citizenship. Technology coaches are models of digital citizenship and promote best practices in using technology for learning and collaboration.

Content Knowledge and Professional Growth. Technology coaches develop and sustain strong knowledge and skills related to content, pedagogical and technological areas. They demonstrate knowledge of adult learning and leadership.

When included in the vision for developing new coaching programs, these standards can provide a guide to defining the role of coaches who can respond to the needs and circumstances of the context.

\section{Evaluation of Instructional Coaching}

Instructional coaching, as any professional development initiative, requires continuous evaluation established on the base of clear goals. The Coaching for Impact report (2016) suggests taking an approach that includes both multiple measures for evaluating coaches as well as forms of support that can help them improve constantly. Similarly as with the evaluation of teaching, success of coaching can be measured with methods that include "classroom walkthroughs, observation forms, data from satisfaction surveys administered to teachers and principals, disaggregated student data, observations of coaches in action, and anecdotal and qualitative data collected from teams a coach works with, such as ongoing and exit interviews" (The University of Florida Lastinger Center for Learning, \& Learning Forward, \& Public Impact, 2016, p. 14). These methods should provide data that can be analyzed to determine the level of success attained by the coaching program and inform the mechanisms of improvement support that education systems can offer to their coaches.

Collecting data on the implementation of coaching can contribute to the developing research on the effectiveness of this modality of professional development, and also help those creating coaching programs to share their models with other practitioners. Kraft, Blazar and Hogan (2016) identify information that is important to collect and report for both research and implementation purposes. Among the most relevant for evaluating the implementation of instructional coaching programs are: features and approaches of the coaching program; length, frequency, and total number of coaching sessions; length and features of other complementary professional development elements of a coaching model; number of coaches and the support they receive in the program.

In the evaluation of instructional coaching for technology integration, current standards can orient the design of measures to determine the success of coaching programs. To guide the design of evaluation tools, the ISTE standards for coaches (2011) provide a useful framework with areas that coaches are expected to impact. These standards are only guidelines to support the definition of goals, and concrete tools for the evaluation of coaching are to be created once those goals have been determined in the context of a specific program. Existing tools such as The Technology Integration Matrix (Florida Center for Instructional Technology at the University of South Florida, College of 
Education, n/a) and the Rubric for Effective Teacher Technology Use (Johnson \& Mielke, 2013) might be highly informative. The Technology Integration Matrix (TIM) offers a description of uses of technology to enhance learning that can be adapted to define goals for technology coaching. The TIM describes five characteristics of learning environments (active, collaborative, constructive, authentic, and goal-directed) that are associated with five levels of technology integration (entry, adoption, adaptation, infusion, and transformation). The intersection of these learning environments and the levels of technology integration define a matrix describing levels that can help determine the progress of technology integration. If combined with the roles of coaches and their goals, this matrix can be helpful for the evaluation of coaching for technology. Likewise, the Rubric for Effective Teacher Technology Use offers a description of three levels of proficiency (basic, proficient, distinguished) for technology-related competencies grouped in four domains (Planning and Preparation, Classroom Environment, Instruction, and Professional Responsibilities). These domains are part of the Danielson's Framework for Teaching that provides a structure for evaluating teaching that can serve as input for evaluating areas of coaching for technology integration. also help improve the quality of experience for teachers. For instance, online video-sharing platforms create a way to share exemplar videos with teachers (Kurz et al., 2017). Other platforms have now been created that allow teachers and coaches to interact with uploaded classroom videos, resulting in more timely feedback. In addition to these benefits, these experiences serve as a model to use technology in meaningful ways in service of a larger goal, in this case, the coaching of teachers.

Online platforms facilitate making teaching public to other teachers and support virtual collaboration among teachers. Open platforms such as The Teaching Channel and the Carnegie Foundation's Gallery of Teaching and Learning support sharing classroom videos and commenting on what can be observed in the videos. Other platforms offer schools and districts the possibility of sharing video in a secure space and support teachers and administrators to engage in watching and analyzing video virtually. One such platform is the Talent platform developed by Torsh. These technology-based tools can contribute to establishing coaching as an ongoing professional development strategy where the sharing of videos as documents of practice is facilitated, making possible the collaborative analysis of teaching for improvement.

\section{Technology Tools for Implementing Coaching}

The advance of technological tools impacts not only teaching but also coaching. As stated previously, the possibility of virtual coaching allows for coaches to spend more time coaching and less time travelling to school sites (White et al., 2015). While video-sharing and online conference platforms can pose a challenge to teachers who are not as comfortable with technology, they have benefits that outweigh the challenges. In addition to helping coaching happen in more efficient ways, technology can 


\section{Conclusion}

In conclusion, there is still much to be explored and studied when it comes to creating and implementing impactful coaching programs. Just like there isn't one way to teach, there isn't one way to coach. However, we would like to make some suggestions, based on the existing literature:

Coaching is most meaningful to teachers when it is content-specific and stimulates collaboration between coaches and teachers in a coaching relationship.

Long-term coaching is more impactful than one-shot professional development opportunities because it allows for more responsive coaching and relationship-building between the coach and teacher, in turn having the most impact on the teacher's practice.

Coaching for technology integration should be based in the understanding that technology is in service of specific content and supports developing higher order skills as well as effective teaching practices.

Salavert (2015) poses the question: "Is there a difference in meaning between empowering teachers and coaching teachers?" Perhaps "empowering" teachers is what Elena Aguilar would consider the goal of what she terms "transformational coaching" in her book The Art of Coaching (2013). Whatever the term used, it is important to strive for a coaching model that impacts teachers enough for them to then have the beliefs and tools needed to impact their classrooms and schools. In his Ted Talk "How great leaders inspire action," Simon Sinek argues that the success of certain organizations or individuals all comes down to what he terms the "what, how, and why." He states that everyone knows what they do, some know how they do what they do, but very few know why they do what they do. By analyzing the success of certain organizations like Apple or individuals like Martin Luther King, Jr., he has determined that the "inspired" ones think from the inside-out. Rather than starting from what's "clear" (what we do), they begin from the "fuzzy" (why we do what we do). These successful individuals and organizations know what their purpose is, and because they lead with their purpose, they are able to impact those around them and get their "clients" on board.

The time has come for us in the world of education to lead with our "why." We must ask ourselves questions like: Why are we coaching? Why is the use of technology important in classrooms? Why is coaching a powerful avenue to support technology integration in teaching and learning? Why are we asking students to do what we are having them do? Only then can we create a "how" and "what" that best serves our students.

\section{This project is made possible with the generous support of Google.}




\section{References}

Aguilar, E. (2013). The Art of Coaching: Effective Strategies for School

Transformation. San Francisco, CA: Jossey-Bass.

Blazar, D., \& Kraft, M. A. (2015). Exploring Mechanisms of Effective Teacher Coaching. Educational Evaluation and Policy Analysis, 37(4), 542-566. https://doi.org/10.3102/0162373715579487

Cornett, J., \& Knight, J. (2009). Research on coaching. In Coaching:

Approaches and Perspectives (pp. 192-216). SAGE Publications.

Darling-Hammond, L., Wei, R. C., Andree, A., Richardson, N., \& Orphanos, S. (2009).

Professional Learning in the Learning Profession: A Status Report on Teacher Development in the United States and Abroad (p. 36). National Staff Development Council.

Darling-Hammond, L., Zielezinski, M. B., \& Goldman, S. (2014). Using Technology to Support At-Risk Students' Learning. Palo Alto, CA: Alliance for Excellent Education and Stanford Center for Opportunity Policy in Education.

Desimone, L. M. (2009). Improving Impact Studies of Teachers' Professional Development: Toward Better Conceptualizations and Measures. Educational Researcher, 38(3), 181-199.

Devine, M., Meyers, R., \& Houssemand, C. (2013). How can Coaching Make a Positive Impact Within Educational Settings? Procedia - Social and Behavioral Sciences, 93, 1382-1389. https://doi.org/10.1016/j.sbspro.2013.10.048

Dinse de Salas, S., Rohlfs, C., \& Spannagel, C. (2016). Coaching teachers in using technology. In Proceedings of EdMedia: World Conference on Educational Media and Technology 2016. Vancouver, BC, Canada: Association for the Advancement of Computing in Education (AACE).

Ertmer, P. A., \& Ottenbreit-Leftwich, A. (2013). Removing obstacles to the pedagogical changes required by Jonassen's vision of authentic technology-enabled learning.

Computers \& Education, 64, 175-182. https://doi.org/10.1016/j.compedu.2012.10.008

Florida Center for Instructional Technology at the University of South Florida, College of Education. (n/a). The Technology Integration Matrix. Retrieved from https://fcit. usf.edu/matrix/wp-content/uploads/2016/11/TIM_Summary_Descriptors.pdf

Garcia, S. G., Jones, D., Holland, G., \& Mundy, M.-A. (2013). Instructional Coaching at Selected Middle Schools in South Texas and Effects on Student Achievement. Journal of Instructional Pedagogies, 11.

Garet, M. S., Wayne, A. J., Stancavage, F., Taylor, J., Eaton, M., Walters, K., ... Hurlburt, S. (2011). Middle School Mathematics Professional Development Impact Study: Findings After the Second Year of Implementation (No. NCEE 2011-4024)). Washington, DC: National Center for Education Evaluation and Regional Assistance, Institute of Education Sciences, U.S. 


\section{References (cont.)}

Hanover Research. (2015). Best Practices in Instructional Coaching (Prepared for lowa Area Education Agencies). Retrieved from https://www.educateiowa.gov/sites/files/ed/documents/Best\%20 Practices\%20in\%20Instructional\%20Coaching\%20-\%20lowa\%20Area\%20Education\%20Agencies.pdf

ISTE. (2011). ISTE Standards for Coaches.

James, J. (2011). Technology, coaching, and community. Learning \& Leading with Technology, 39(2), 48.

Johnson, D., \& Mielke, N. (2013). Rubric for Effective Teacher Technology Use. ASCD. Retrieved from http://www.ascd.org/ASCD/pdf/journals/ed_lead/el201303_johnson_rubric.pdf

Jonassen, D. H. (1996). Computers in the classroom: Mindtools for critical thinking. Columbus, $\mathrm{OH}$ : Merrill/Prentice Hall.

King, D., Neuman, M., Pelchat, J., Potochnick, T., Rao, S., \& Thompson, J. (2004). Instructional Coaching. Professional Development Strategies That Improve Instruction. Annenberg Institute for School Reform.

Knight, J. (2007). Instructional Coaching: A Partnership Approach to Improving Instruction. SAGE Publications. Retrieved from https://books.google.com/books?id=6xhT3r1KERYC

Knight, J. (2009). Coaching: Approaches and Perspectives. SAGE Publications.

Kraft, M. A., Blazar, D., \& Hogan, D. (2016). The Effect of Teacher Coaching on Instruction and Achievement: A Meta-Analysis of the Causal Evidence. Brown University Working Paper.

Kurz, A., Reddy, L. A., \& Glover, T. A. (2017). A Multidisciplinary Framework of Instructional Coaching. Theory into Practice, 56(1), 66-77. https://doi.org/10.1080/00405841.2016.1260404

Lofthouse, R., Leat, D., Towler, C., Hall, E., \& Cummings, C. (2010). Improving coaching: evolution not revolution, research report. CfBT Education Trust. Retrieved from http://dev.cfbtoman. com/wp-content/uploads/2017/04/r-processes-outcomes-of-coaching-full-2010.pdf

Reinhart, J. M., Thomas, E., \& Toriskie, J. M. (2011). K-12 Teachers: Technology Use and the Second Level Digital Divide. Journal of Instructional Psychology, 38(3/4), 181-193.

Russo, A. (2004). School-Based Coaching. A revolution in professional development-or just the latest fad? Harvard Education Letter, 20(4).

Salavert, R. (2015). Coaching: An Apprenticeship Approach for the 21st Century. International Journal of Educational Leadership and Management; Vol 3, No 1 (2015): January. https://doi.org/10.4471/ijelm.2015.02 


\section{References (cont.)}

Sanders, W. L., Wright, S. P., \& Horn, S. P. (1997). Teacher and Classroom

Context Effects on Student Achievement: Implications for Teacher Evaluation.

Journal of Personnel Evaluation in Education, 11(1), 57.

Sutton, J. T., Burroughs, E. A., \& Yopp, D. A. (2011). Coaching knowledge: Domains

and definitions. Journal of Mathematics Education Leadership, 13(2), 12-20.

The University of Florida Lastinger Center for Learning, \& Learning Forward, \& Public Impact. (2016). Coaching for Impact: Six Pillars to Create Coaching Roles That Achieve Their Potential to Improve Teaching and Learning. Gainesville: University of Florida Lastinger Center; Oxford, OH: Learning Forward; and Chapel Hill, NC: Public Impact. Retrieved from https://learningforward.org/publications/coaching-for-impact

U.S. Department of Education, Office of Educational Technology. (2017). Reimagining the Role of Technology in Education: 2017 National Education Technology Plan Update. Washington, D.C.

Veenman, S., Denessen, E., Gerrits, J., \& Kenter, J. (2001). Evaluation of a coaching programme for cooperating. Educational Studies, 27(3), 317-340.

White, A. S., Howell Smith, M., Kunz, G. M., \& NUgent, G. C. (2015). Active Ingredients of Instructional Coaching: Developing a Conceptual Framework (R2Ed Working Paper No. 2015-3). 